\title{
ПРАВОВАЯ ПРИРОДА ИСПОЛНЕНИЯ ОБЯЗАТЕЛЬСТВА
}

\begin{abstract}
АНнОТАЦИЯ. В настоящее время исполнение обязательства является с точки зрения определения его правовой природы одним из наиболее дискуссионных вопросов. Анализ современной юридической литературы свидетельствует об отсутствии единообразия в понимании правовой природы действий по исполнению обязательства. В статье рассматриваются основные подходы к определению правовой природы исполнения обязательства (в том числе исполнение - сделка; исполнение - юридический поступок; исполнение - фактическое действие и др.), дается их критическая оценка, а также анализируется правовая природа действий. Обосновывается, что исполнение обязательства включает в себя большое разнообразие возможных действий, не обладающих единой правовой природой. Делается вывод, согласно которому, в большинстве случаев, действия по исполнению обязательств, в том числе передача вещи, выполнение работы и оказание услуги, являются юридическими поступками.

кЛЮЧЕВЫЕ СЛОВА. Исполнение обязательства; юридический поступок; юридический акт; юридический факт; волеизъявление; передача вещи.

ИНФОРМАЦИЯ О СТАТЬЕ. Дата поступления 2 июля 2015 г.; дата принятия к печати 28 декабря 2015 г.; дата онлайн-размещения 31 мая 2016 г.
\end{abstract}

Ye. V. Titov

Baikal State University, Irkutsk, Russian Federation

\section{LEGAL NATURE OF ENFORCING THE OBLIGATION}

\begin{abstract}
At the present time, enforcing the obligation is, in terms of determining its legal nature, one of the most controversial issues. Analysis of the current legal literature testifies absence of uniformity in understanding the legal nature of actions in enforcing the obligation The article considers main approaches to identifying the legal nature of enforcing the obligation (including: enforcement - transaction; enforcement - legal act; enforcement - physical act, and others), gives their critical assessment, as well as analyses the legal nature of the actions. It substantiates that enforcing the obligation includes a wide variety of possible actions that do not have a unified legal nature. A concludes is made according to which in majority of cases the actions of enforcing the obligation, including transferring things, executing work and rendering services are legal acts.

KEYWORDS. Enforcing the obligation; legal act; legal fact; act in law, expression of will, transfer of things.
\end{abstract}

ARTICLE INFO. Received July 2, 2015; accepted December 28, 2015; available online May 31, 2016.

Определение правовой природы исполнения обязательства является одним из наиболее дискуссионных и принципиальных вопросов, имеющих не только существенное теоретическое, но также и практическое значение. Данный вопрос, хотя и обсуждается в литературе довольно часто, до настоящего времени не является решенным.

Проблемы правильной квалификации отдельных видов действий по исполнению обязательства ставят перед учеными и юристами-практиками множество вопросов. В первую очередь о правильном выборе правовой нормы, которая может применяться только к конкретному виду юридических фактов. Так, по утверждению В. С. Толстого, если исполнение является юридическим поступком, то применяются правила только об исполнении обязательств, если же сделкой, то, помимо

(C) E. B. Титов, 2016

\section{Baikal Research Journal}


правил об исполнении, также подлежат применению нормы о сделках, если соглашение, то еще и нормы о договорах [1, с. 22-23].

Как справедливо отмечает С. В. Сарбаш, «проблема юридической природы исполнения прежде собственного разрешения требует ответа на вопрос о возможности выработки единой унифицированной концепции исполнения обязательства. Этот вопрос - ключевой. Можно ли подвести под всякое исполнение, независимо от его вида, унифицированное понятие, которое охватывало бы любое и каждое исполнение обязательства?» [2, с. 29]. Можно и нужно выработать унифицированное понятие исполнения обязательства, однако это не означает, что действия, составляющие предмет исполнения, имеют одинаковую правовую природу.

Нельзя со всей очевидностью выделить господствующее мнение по данному вопросу. Одни авторы полагают, что исполнение обязательства является сделкой, поскольку оно, во всяком случае, направлено на возникновение, изменение либо прекращение правоотношения [Там же, с. 50-55]. К такому выводу ученые приходят потому, что исполнение обязанности обладает всеми признаками сделки, а именно: исполнение есть действие правомерное; влечет прекращение обязанности должника (юридические последствия) и должник стремится освободиться от этой обязанности, следовательно, исполнение - действие, направленное именно на те правовые последствия, которые оно вызывает [1, с. $23 ; 2$, с. $52 ; 3$, с. 188].

Другие квалифицируют исполнение обязательства как юридический поступок, поскольку направленность воли на исполнение не является обязательной (право придает значение исполнению вне зависимости от наличия такой направленности) [4, с. 154].

Кроме того, встречаются мнения, согласно которым исполнение выступает и как фактическое действие, и как результативное действие, юридический акт особого рода или как вещная сделка (односторонняя либо соглашение) [5, с. 55]. Обзор различных точек зрения на правовую природу исполнения наиболее подробно провел С. В. Сарбаш [2, с. 27-83]. Обзор иностранной литературы можно найти у K. Larenz [6, S. 235].

Правоприменительная практика испытывает затруднения при квалификации действий по исполнению обязательства. Судьи по-разному расценивают такие действия ${ }^{1}$, даже обсуждая эту проблему в высших судебных инстанциях. Так, В. В. Витрянский высказался на этот счет следующим образом: «это же глобальная проблема, что представляют собой действия по исполнению обязательства - юридический поступок или сделку, или ни то ни другое?» [3, с. 190].

Как представляется, неправильное понимание правовой природы действий по исполнению обязательства кроется в недостатках учения о юридических фактах, а именно, в нечетком разграничении юридических действий. В таких условиях, когда ни юридические акты, ни юридические поступки не обладают достаточно четко определенными признаками и критериями разграничения, не представляется возможным и причисление к этим конструкциям отдельных разновидностей юридических фактов [7, с. 70-71].

Исполнением обязательства является совершение действий, предусмотренных в данном обязательстве в точном соответствии с условиями этого обязательства. Объединение законодателем различных действий, составляющих предмет обязательства и необходимых для «нормального» завершения данного обязательства, единым понятием «исполнение» не свидетельствует об однообразии таких действий с точки зрения теории юридических фактов. Объединяет их не единая правовая природа, а то, что все они влекут прекращение обязательства в соответствии с его условиями. Это обстоятельство еще не дает право относить все действия по исполнению к одной

${ }^{1}$ Решение Арбитражного суда Иркутской области от 2 марта 2010 г. по делу № A19-28382/09 // СПС «Гарант» (документ опубликован не был).

\section{Baikal Research Journal}


разновидности юридических фактов. Порождение определенных правовых последствий, в том числе прекращение обязательства - признак юридических фактов вообще, в равной степени присущий и сделкам, и юридическим поступкам, и всем иным видам юридических фактов.

Исполнение обязательства - понятие собирательное, включающее в себя различные варианты поведения, предусмотренные обязательством (где одно лицо обязано предоставить исполнение, а другое, соответственно, требовать такого предоставления) [8]. Сколько разнообразным является предмет обязательства, столько разнообразны и действия по его исполнению. Исполнение может заключаться в перенесении права собственности на контрагента (купля-продажа, дарение, мена и т. д.), предоставление вещи в пользование (аренда, ссуда), выполнении работы (подряд, опытно-конструкторские работы), оказание услуги (консультационного, медицинского и иного характера) [9, с. 18]. Так, например, исполнением предварительного договора будет являться заключение основного договора, что по правовой природе, несомненно, является сделкой.

Поскольку под понятием исполнения объединены различные по правовой природе действия, то вопрос об определении «правовой природы разнородных по правовой природе действий» представляется изначально некорректным.

Исполнение может совершаться либо в форме юридического акта, например, соглашения, заключаемого сторонами (такие акты в литературе нередко обозначаются специальными терминами - вещная, абстрактная, распорядительная сделки) $\left[10\right.$, c. 23], либо в форме юридического поступка ${ }^{2}$ (передачи вещи, выполнения работы, оказания услуги) [11, с. 151-152]. Существование третьего варианта невозможно, поскольку как события, так и неправомерные действия не могут составлять предмета обязательства, а, следовательно, не являются его исполнением.

Исполнение обязательства может заключаться в выполнении исключительно материальных действий, например выполнение работы (постройка здания, уборка помещения и т. д.). В большинстве обязательств именно такие действия являются предметом исполнения.

Однако исполнение может ограничиваться лишь соглашением, либо односторонним волеизъявлением, например, заключение основного договора (который, в свою очередь требует исполнения ${ }^{3}$ будет исполнением договора предварительного; уступка требования ${ }^{4}$, в частности, по договору финансирования под уступку денежного требования (ст. 824 Гражданского кодекса РФ); в соответствии с ч. 1 ст. 971 Гражданского кодекса РФ поверенный по договору поручения обязуется совершить от имени и за счет доверителя определенные юридические действия, которые могут быть в том числе и сделками, и иными разновидностями юридических актов, а их выполнение будет являться исполнением поручения. Разделение исполнения на две составные части - волеизъявление (сделка, акт) и материальные действия (поступки, фактические действия) нередко встречается в юридической литературе [12, с. 26].

Игнорирование наличия двух различных по правовой природе действий, объединяемых наименованием «исполнение» ведет к существенным расхождениям в юридической квалификации действий по исполнению. Понимание под исполнением одного только соглашения (сделки) не отражает сущность данного явления.

\footnotetext{
${ }^{2}$ Под юридическими поступками нами понимаются действия, воздействующие на предметы материального мира (материальные действия) и влекущие предусмотренные законодательством правовые последствия.

${ }^{3}$ Возможно представить ситуацию, когда заключение основного договора само по себе полностью удовлетворит интерес кредитора. Так, при продаже вещи, уже находящейся во владении кредитора, передача ее не требуется - передача по правилу «короткой руки» (brevi manu - лат.).

${ }^{4}$ В ч. 1 ст. 382 Гражданского кодекса РФ уступка права прямо названа сделкой, это следует и из систематического толкования § 1 гл. 24 указанного документа.
}

\section{Baikal Research Journal}


То обстоятельство, что надлежащее исполнение обязательства влечет его прекращение (что прямо следует из закона - ч. 1 ст. 408 Гражданского кодекса РФ), еще не свидетельствует о «направленности воли на прекращение обязательства». Именно как волеизъявление, «направленное» на динамику правоотношения, ст. 153 Гражданского кодекса РФ определяет сделку, что позволяет ученым причислять все подобного рода действия к сделкам.

По утверждению В. С. Толстого, «действия, совершенные с известной целью, принято считать направленными на эту цель» [1, с. 23]. В таких условиях любое действие, влекущее какие-либо правовые последствия, и, если лицу об этом известно, должно считаться сделкой. При совершении юридического поступка лицу тоже, как правило, известно какие именно правовые последствия порождает его действие, однако это не позволяет нам утверждать ни то, что эти действия направлены на правовые последствия, ни тем более, что они являются сделками. В противном случае не было бы необходимости вообще классифицировать юридические действия, поскольку все они «подпадали бы под понятие сделки» .

При исполнении обязательства воля исполнителя может быть вовсе не направлена на прекращение обязательства, лицо может даже не знать о состоявшемся исполнении, если, например, оно произведено третьим лицом либо по ошибке. Передавая товар, лицо ставит перед собой ближайшую цель вручение вещи, передачу ее во владение контрагента, а не прекращение обязательства; выполняя определенную работу или совершая услугу, лицо не ставит перед собой цели прекратить обязательство.

Следуя логике авторов, отстаивающих сделочную природу любого действия по исполнению ввиду его направленности на прекращение обязательства, следовало бы признать, что одно и то же действие с формальной точки зрения, выполненное по обязательству и вне обязательства, представляет собой различные разновидности юридических фактов. Так, создавая скульптуру по заказу, скульптор выполняет обязательство, значит, совершает сделку, а создавая ее для себя - юридический поступок. Если в первом случае действие направлено на прекращение обязательства, а не на создание скульптуры, то на что же тогда направлено второе действие? Вопрос риторический, поскольку не может быть действий, влекущих правовые последствия, и совершенных вовсе без всякой цели.

Прекращение правоотношения путем совершения передачи вещи, выполнения работы либо оказания услуги, является, как совершенно справедливо отмечает Е. Я. Мотовиловкер, «не конкретным практическим результатом действия должника как определенного поведенческого акта..., не его естественным итогом, а ...его побочным юридическим последствием как акта исполнения обязанности» $[13$, с. 86]. Такие действия не являются сделками, да и вообще юридическими актами, поскольку не представляют собой волеизъявления. «Именно потому, что, исполняя договорную обязанность, должник не занимается волеизъявлением о ее аннулировании (не этого действия ждет от него кредитор), данное действие ни под каким предлогом не может объявляться правопрекращающей сделкой» [Там же, с. 87]. Вручение вещи, оказание услуги и выполнение работы представляют собой действия, требующие приложение физического усилия и мышечной работы, что не характерно для волеизъявления, заключающегося в выражении намерения (воли) путем словесного высказывания (устно или письменно) [Там же, с. 86].

Юридические акты, как правило, не в состоянии порождать того эффекта, ради которого стороны вступали в правоотношение. Если признать, что исполнение ограничивается одним только волеизъявлением без совершения материального действия, то все правоотношение будет состоять только из актов (сделок), а значит стороны никогда не смогут удовлетворить свои потребности - вещь не будет передана, работа не будет выполнена, услуга не будет оказана, будет только ситуация, при которой одна сторона

\section{Baikal Research Journal}


вечно вправе требовать, а вторая - вечно обязана передать, выполнить и т. д. Другими словами, правоотношение будет состоять только из изъявлений воли, но повторное изъявление воли не в состоянии исполнить волю, выраженную при заключении сделки [13, с. 86-89]. Стороны договариваются, как правило, не о выражении воли, а о произведении реальных, фактических действий, способных произвести перемены в имущественной сфере друг друга, ожидают не юридического, а фактического, экономического эффекта от исполнения (приобретения вещи во владение, удовлетворение оказанной услугой и т. д.). В противном случае содержанием правоотношения стоило бы признать не выполнение необходимых, оговоренных сторонами действий, а выражение воли о прекращении обязательства. Исполнением договорного обязательства в таком случае являлось бы заявление должника о намерении прекратить обязательство. Очевидно, что такое волеизъявление не имеет ничего общего с исполнением.

В случае признания исполнения юридическим актом невозможно представить себе ситуацию, при которой исполнение совершает не сам должник, а третье лицо. Поскольку третье лицо не является стороной правоотношения, то никакой сделки, прекращающей данное правоотношение, совершать не вправе. Кроме того, надлежаще исполненное обязательство прекращается и в том случае, если воля лица его исполнить отсутствовала (по ошибке, по принуждению и т. д.).

Юридические акты совершаются путем волеизъявления, т. е. прямого направления воли к восприятию другим лицом (лицами) - заявления, требования, просьбы, соглашения и т. д. Такие изъявления воли формальны, и право нередко предъявляет особые требования к их форме для облегчения фиксации и доказывания. Юридические поступки не изъявления воли и проявляются они во внешнем мире иначе, воздействуя не на волю лица, а на предметы материального мира, ввиду чего имеют форму физического (материального) действия, не могут быть ни устными, ни письменными. Юридическими поступками являются выполнение работы и оказание услуги, а также передача вещи (как акт фактического вручения).

Самым распространенным случаем исполнения обязанности выступает передача вещи (traditio - лат.). Нередко для исполнения обязательства по перенесению права на вещь необходимо помимо физического вручения этой вещи (а иногда вручение вовсе невозможно - вещь уже находится во владении приобретателя, либо свойство вещи не позволяет ее «вручить», например, земельный участок) выполнение ряда сопутствующих формальностей, например, подписание акта передачи недвижимости. Как представляется, это обстоятельство и вводит юристов в заблуждение при определении правовой природы передачи вещи.

К такому формализму при передаче имеются известные исторические предпосылки. Передача вещи для того, чтобы иметь юридическую значимость испокон веков сопровождалась особыми обрядами, как правило, в торжественной форме с присутствием свидетелей. Так, например, в Древнем Риме обязательство могло прекратиться только в той же форме, что и возникло, путем совершения «обратного действия» (actus contrarius - лат.). При этом nexus прекращался в форме особого обряда с весами - solutio per aes et libram . Составление документа о состоявшейся уплате в присутствии пяти свидетелей - securitas и другие. Однако уже в классическом римском праве простое материальное исполнение стало «очевидным и естественным способом прекращения правоотношения» [14, с. 518-519].

Такие обряды служили известной практической цели - публичному удостоверению перехода права, имевшему впоследствии доказательственное значение. В настоящее время в предмет доказывания по конкретному делу может входить факт состоявшейся передачи, в связи с чем у сторон возникает желание заблаговременно позаботиться о придании акту передачи публичности (вручение происходит при свидетелях, подписываются особые акты передачи и т. д.). Нередко законодатель сам опреде-

\section{Baikal Research Journal}


ляет такие требования к передаче - например, п. 1 ст. 563 Гражданского кодекса РФ устанавливает, что «передача предприятия продавцом осуществляется по передаточному акту», и связывает такую передачу не с фактическим вручением, а с моментом подписания такого акта (п. 2 ст. 563). Подобные требования содержаться в п. 1. ст. 556, 655,659 Гражданского кодекса РФ и др. Многие другие отечественные и зарубежные нормативные акты содержат особые требования к передаче вещи. В связи с чем возникает иллюзия о «формальности» передачи, необходимости придания передаче особой формы, возможности распространения на акт передачи положений о форме сделки.

Как отмечает Л. Ю. Василевская, в Германии при невозможности реальной передачи вещи (при приобретении недвижимости), использовали особую церемонию инветситуру (die Investitur - нел.), состоявшую из символических и реальных действий (оставление владения, отказ от него, освобождение, бросание соломинки, куска земли и т. д.), которую автор характеризует как самостоятельный вещный договор [12, с. 42-43]. Такая «формальность» заменяла реальную передачу вещи. При продаже движимой вещи, в инвеституре, соответственно, не было необходимости.

Определенная обрядность сохраняется и, как представляется, во всевозможных суррогатах традиции - передача по правилу «длинной руки» (traditio longa manu - лат.), передача по правилу «короткой руки» (traditio brevi manu - лат.), символическая передача (traditio symbolica - лат.).

В германском праве, указывает Р. С. Бевзенко, сделкой признается не само фактическое вручение вещи, а соглашение о передаче права, соединяемое с передачей вещи. «Таким образом, вещная сделка германского права - это вещный договор плюс традиция. При этом традиция выступает вовсе не как сделка, а как фактическое действие, или, точнее - Realakt» [15, с. 18]. Еще Ф. Савиньи отмечал, что передача состоит из двух разновидностей юридически значимых действий - из особого вещного договора и формального акта передачи (действительной передачи владения) [16, с. 37-42]. Данные выводы нашли закрепление и в германском гражданском уложении, в 929 которого говорит о двух элементах передачи движимой вещи - фактической передачи вещи и соглашения о передачи права на вещь. Одного соглашения достаточно только в случае, если приобретатель уже владеет вещью. Последнее означает, что приобретатель уже завладел вещью иным «материальным» действием - вещь была передана ранее по иному основанию, нашел, осуществил захват, произвел из чужих материалов и т. д.

В законодательстве передача понимается именно как «вручение» вещи, «сдача» перевозчику (ст. 224 Гражданского кодекса РФ), т. е. материальное, физическое действие. Такое понимание передачи характерно и для иностранного законодательства: «В соответствии со ст. 1604 ФГК передача - это перенесение проданной вещи во власть и владение покупателя. Аналогичное определение содержится в Законе о продаже товаров Англии 1979 г. и Едином торговом кодексе США, где передача (delivery) определяется как добровольное перенесение владения» [5, с. 105], т. е. прежде всего - «физическая передача» [17, с. 105].

К таким видам исполнения обязательства, как передача вещи, выполнение работы либо оказание услуги, не применимы нормы о сделках, ни о форме, ни о недействительности (в том числе реституции), так как они, будучи материальными (физическими) действиями, всегда действительны, и именно поэтому для восстановления положения, существовавшего до совершения их, требуется совершение «обратного действия» (например, обратной передачи), что присуще только действиям, производящим перемены в материальном мире, т. е. юридическим поступкам.

Таким образом, исполнение обязательства может заключаться в выполнении разнородных по правовой природе действий, которые могут являться как юридическими актами, так и юридическими поступками. Поэтому вопрос о том, чем же является

\section{Baikal Research Journal}


исполнение «вообще» (сделкой, иной разновидностью юридического акта либо юридическим поступком) не может найти однозначного ответа. Исполнение может совершаться как в виде юридического акта, так и в виде юридического поступка.

В подавляющем большинстве случаев действия по исполнению являются юридическими поступками, к ним следует отнести передачу вещи, выполнение работы и оказание услуги. Лишь в некоторых случаях действия по исполнению являются юридическими актами, например, совершенные в виде цессии, либо перевода долга по договору, заключения основного договора, совершение сделки представителем по договору поручения.

\section{Список использованной литературы}

1. Толстой В. С. Исполнение обязательств / В. С. Толстой. - М. : Юрид. лит., 1973. - 208 с.

2. Сарбаш С. В. Исполнение договорного обязательства / С. В. Сарбаш. - М. : Статут, 2005. $-636 \mathrm{c}$.

3. Обсуждение проблемных вопросов договора комиссии / подгот. А. В. Егоров / / Вестник Высшего Арбитражного Суда Российской Федерации. - 2004. - № 8. - С. 186-209.

4. Красавчиков О. А. Юридические факты в советском гражданском праве / О. А. Красавчиков. - М. : Госюриздат, 1958. - 183 с.

5. Тузов Д. О. О традиции как вещном договоре в российском гражданском праве / Д. О. Тузов // Вестник Высшего Арбитражного Суда Российской Федерации. - 2007. № 8. - C. 54-79.

6. Larenz K. Lehrbuch des Schuldrechts. Bd. 1. Allgemeiner Teil., 14, neubearb. Aufl. / K. Larenz ; Bearb. Canaris C.-W. - München : Beck, 1987. - 541 S.

7. Титов Е. В. Юридические действия, квалифицируемые в качестве юридических поступков / Е. В. Титов // Пролог: журнал о праве. - 2014. - Т. 2, № 4. - С. 68-72.

8. Виниченко Ю. В. Требования в праве (общетеоретический аспект) [Электронный ресурс] / Ю. В. Виниченко // Известия Иркутской государственной экономической академии (Байкальский государственный университет экономики и права). -2010 . - № 6. - Режим доступа : http://eizvestia.isea.ru/reader/article.aspx?id=13987.

9. Далбаева Н. Н. Договоры о выполнении работ и оказании услуг : курс лекций / Н. Н. Далбаева. - Иркутск : Изд-во БГУЭП, 2010. - 96 с.

10. Суханов Е. А. О видах сделок в германском и в российском гражданском праве / Е. А. Суханов // Вестник гражданского права. - 2006. - № 2. - С. 5-26.

11. Schmidt R. BGB Allgemeiner Teil: Grundlagen des Zivilrechts; Methodik der Fallbearbeitung. Aus. 10, völlig neu bearb. und aktualisierte Aufl. / R. Schmidt. Grasberg bei Bremen : Schmidt, 2014. - $460 \mathrm{~S}$.

12. Василевская Л. Ю. Вещные сделки по германскому праву: методология гражданско-правового регулирования : дис. ... д-ра юрид. наук : 12.00.03 / Л. Ю. Василевская. - М., 2004. $-578 \mathrm{c}$.

13. Мотовиловкер Е. Я. Спорные вопросы теории сделок / Е. Я. Мотовиловкер // Вестник гражданского права. - 2011. - № 4. - С. 84-101.

14. Дождев Д. В. Римское частное право : учебник / Д. В. Дождев ; под общ. ред. В. С. Нерсесянца. - 2-е изд., изм. и доп. - М. : Норма, 2005. - 784 с.

15. Бевзенко Р. С. Зачет в гражданском праве: опыт исследования теоретической конструкции и обобщения судебной практики / Р. С. Бевзенко, Т. Р. Фахретдинов. - М. : Статут, 2006. - $172 \mathrm{c}$.

16. Savigny F. C. v. Das Recht des Besitzes Nachdr. Aus. der Ausg. Gießen, Heyer, 1803 / F. C. v. Savigny. - Goldbach : Keip, 1997. - $495 \mathrm{~S}$.

17. Кастрюлин Д. Ф. Переход риска случайной гибели или случайного повреждения товара по договору международной купли-продажи : дис. ... канд. юрид. наук : 12.00.03 / Д. Ф. Кастрюлин. - Саратов, 2003. - 190 с.

\section{References}

1. Tolstoy V. S. Ispolnenie obyazatel'stv [Enforcement of obligations] Moscow, Yuridicheskaya Literature Publ., 1973. 208 p.

\section{Baikal Research Journal}


2. Sarbash S. V. Ispolnenie dogovornogo obyazatel'stva [Enforcement of contractual obligations]. Moscow, Statut Publ., 2005. 636 p.

3. Yegorov A. V. (ed.). Discussion of problematic issues in terms of commission agreement. Vestnik Vysshego Arbitrazhnogo Suda Rossiiskoi Federatsii = Bulletin of Supreme Arbitration Court of the Russian Federation, 2004, no. 8, pp. 186-209. (In Russian).

4. Krasavchikov O. A. Yuridicheskie fakty $v$ sovetskom grazhdanskom prave [Legal facts in Soviet civil law]. Moscow, Gosyurizdat Publ., 1958. 183 p.

5. Tuzov D. O. On tradition as an in rem transaction in Russian civil law. Vestnik Vysshego Arbitrazhnogo Suda Rossiiskoi Federasii = Bulletin of Supreme Arbitration Court of the Russian Federation, 2007, no. 8. pp. 54-79. (In Russian).

6. Larenz K., Canaris C.-W. Bearb. Lehrbuch des Schuldrechts. Bd. 1. Allgemeiner Teil., 14, neubearb. Aufl. München, Beck, 1987. $541 \mathrm{~s}$.

7. Titov E. V. Legal acts qualified as legal steps. Prolog: zhurnal o prave = Prolog: Journal about Law, 2014, vol. 2, no. 4, pp. 68-72. (In Russian).

8. Vinichenko Yu. V. Requirements in law (general theoretical aspect). Izvestiya Irkutskoy gosu darstvennoy ekonomicheskoy akademii (Baykalskiy gosudarstvennyy universitet ekonomiki i prava) = Bulletin of Irkutsk State Economics Academy (Baikal State University of Economics and Law), 2010, no. 6. Available at: http://eizvestia.isea.ru/reader/article.aspx?id=13987. (In Russian).

9. Dalbayeva N. N. Dogovory o vypolnenii rabot i okazanii uslug [Contracts of executing work and rendering services]. Irkutsk, Baikal State University of Economics and Law Publ., 2010. 96 p.

10. Sukhanov E. A. On types of transactions in German and Russian Civil Law. Vestnik grazhdanskogo prava = Civil Law Review, 2006, no. 2, pp. 5-26. (In Russian).

11. Schmidt R. BGB Allgemeiner Teil: Grundlagen des Zivilrechts; Methodik der Fallbearbeitung. Aus. 10, völlig neu bearb. und aktualisierte Aufl. Grasberg bei Bremen, Schmidt, 2014. $460 \mathrm{~s}$.

12. Vasilevskaya L. Yu. Veshchnye sdelki po germanskomu pravu: metodologiya grazhdans ko-pravovogo regulirovaniya. Dokt. Diss. [In rem transactions in terms of German law: methodology of civil-legal regulation. Doct. Diss.]. Moscow, 2004. 578 p.

13. Motovilovker E. Ya. Disputable points of odd-lot theory. Vestnik grazhdanskogo prava= Civil Law Review, 2011, no. 4, pp. 84-101. (In Russian).

14. Dozhdev D. V.; Nersesyants V. S. (ed.). Rimskoe chastnoe pravo [Roman Private Law]. $2^{\text {nd }}$ ed. Moscow, Publ., 2005. 784 p.

15. Bevzenko R. S., Fakhretdinov T. R. Zachet $v$ grazhdanskom prave: opyt issledovaniya teoreticheskoi konstruktsii i obobshcheniya sudebnoi praktiki [Set-off in civil law: experience of investigating theoretical construction and case law analyses]. Moscow, Statut Publ., 2006. 172 p.

16. Savigny F. C. v. Das Recht des Besitzes Nachdr. Aus. der Ausg. Gießen, Heyer, 1803. Goldbach, Keip, 1997. 495 s.

17. Kastryulin D. F. Perekhod riska sluchainoi gibeli ili sluchainogo povrezhdeniya tovara po dogovoru mezhdunarodnoi kupli-prodazhi. Kand. Diss. [Transition of accidental loss risks or accidental commodity damage risks in terms of international purchase and sale contract. Cand. Diss.]. Saratov, 2003. 190 p.

\section{Информация об авторе}

Титов Евгений Валерьевич - ассистент, кафедра гражданского права и процесса, Байкальский государственный университет, 664003, г. Иркутск, ул. Ленина, 11, e-mail: bumbala@mail.ru.

\section{Author}

Yevgeny V. Titov - Assistant, Chair of Civil Law and Procedures, Baikal State University, 11 Lenin St., 664003, Irkutsk, Russian Federation; e-mail: bumbala@mail.ru.

\section{Библиографическое описание статьи}

Титов Е. В. Правовая природа исполнения обязательства / Е. В. Титов // Baikal Research Journal. - 2016. - T. 7, № 3. - DOI : 10.17150/2411-6262.2016.7(3).24.

\section{Reference to article}

Titov Ye. V. Legal nature of enforcing the obligation. Baikal Research Journal, 2016, vol. 7, no. 3. DOI : $\underline{10.17150 / 2411-6262.2016 .7(3) .24}$. (In Russian).

\section{Baikal Research Journal}

